\title{
EFEKTIFITAS PENERAPAN FINGER PRINT PADA DINAS PEMBERDAYAAN MASYARAKAT DAN DESA PROVINSI SULAWESI SELATAN
}

\section{The Effectiveness of the Implementation of Finger Print in the Office of Community and Village Empowerment, South Sulawesi Province}

\author{
Wahyudi $^{1}$, Syamsul Bahri ${ }^{2}$, Syamsuddin Maldun ${ }^{2}$ \\ ${ }^{1}$ Dinas Pemberdayaan Masyarakat Provinsi Sulawesi Selatan \\ ${ }^{2}$ Program Studi Ilmu Administrasi Negara, Program Pascasarjana, Universitas Bosowa \\ Email: wahyudipmd2009@gmail.com
}

Diterima: 24 Agustus 2020

Dipublikasikan: 07 Desember 2020

\begin{abstract}
ABSTRAK
Pendisiplinan pegawai sangat perlu untuk meningkatkan citra kerja, dan kinerja pegawai. Salah satu bagian dalam upaya pendisiplinan tersebut adalah penggunaan alat absensi dalam bentuk finger print. Penerapan absensi finger print di Dinas Pemberdayaan Masyarakat dan Desa Provinsi Sulawesi Selatan juga dapat memudahkan atasan untuk melihat tingkat kedisiplinan kehadiran dari masing-masing pegawai. Desain penelitian yang digunakan yaitu desain penelitian deskriptif dengan pendekatan kualitatif. Penelitian ini akan dilakukan di Dinas Pemberdayaan Masyarakat dan Desa Provinsi Sulawesi Selatan. Teknik pengumpulan data yang digunakan dalam penelitian ini yaitu: wawancara, observasi, serta dokumen. Untuk melakukan proses analisis data, peneliti akan melakukan tiga tahapan proses, yaitu: 1) Tahapan reduksi data (data reduction); 2) Tahapan penyajian data (data display); 3) Tahapan penarikan kesimpulan atau verifikasi (conclusing drawing verivication). Dalam proses pelaksanaannya keempat indikator yaitu pencapaian target, kemampuan adaptasi, kepuasan kerja dan tanggungjawab berdasarkan temuan di lapangan semuanya dilakukan dengan baik. Kendatipun ada masalah di lapangan namun hal tersebut hanya merupakan masalah teknis yang dapat diatasi dengan mudah dan cermat oleh instansi tersebut. Adapun hambatan dalam mendukung efektifitas pelaksanaan finger print di dinas PMD provinsi Sulawesi Selatan ada dua yaitu persoalan mesin finger print yang salah dalam melakukan identifikasi data pegawai dan adanya mesin eror.
\end{abstract}

Kata Kunci : Efektifitas, Finger Print, Dinas PMD, Sulawesi Selatan

\begin{abstract}
Employee discipline is very necessary to improve work culture and employee performance. One part of the disciplinary effort is the use of an attendance device in the form of a finger print. The implementation of finger print attendance at the Office of Community and Village Empowerment Service in South Sulawesi Province can also make it easier for superiors to see the disciplinary level of attendance of each employee. The research design used is a descriptive research design with a qualitative approach. This research will be conducted at the Community and Village Empowerment Service of South Sulawesi Province. Data collection techniques used in this study are: interviews, observations, and documents. To carry out the data analysis process, the researcher conducted three stages of process, which are: 1) Data reduction; 2) data display; 3) drawing conclusions or verification. In the implementation process, the four indicators, which are target achievement, adaptability, job satisfaction and responsibility based on findings in the field are all done well. Even though there are problems during the fieldwork, they are only technical problems that can be resolved easily and carefully by the agency. There are two obstacles in supporting the effectiveness of the implementation of finger print at the PMD office of South Sulawesi province, namely the problem of finger print machines that incorrectly identify employee data and the machine errors.
\end{abstract}

Keywords: Effectiveness, Finger Print, PMD Office, South Sulawesi

\section{PENDAHULUAN}

Perkembangan ilmu pengetahuan dan teknologi tumbuh saat ini begitu pesat, sehingga membawa perubahan pula dalam kehidupan manusia, maka dari itu, setiap perusahaan diharapkan memiliki berbagai peraturan yang harus ditaati dan memiliki standar yang harus dipenuhi oleh karyawannya. Disiplin merupakan tindakan manajemen untuk mendorong para anggotanya untuk memenuhi peraturan-peraturan yang ada diperusahaan, seperti waktu atau jam kerja, dalam berpakaian, penggunaan peralatan maupun perlengkapan kantor dan lain sebagainya. Menurut Lijan Poltak Sinambela (2016), "disiplin kerja merupakan kemampuan seseorang secara teratur, tekun secara terus menerus dan mampu bekerja sesuai dengan aturan-aturan yang berlaku dan tidak melanggar peraturan yang telah disepakati”.Seiring dengan berjalannya waktu kedisiplinan bukanlah hal yang menjadi prioritas utama bagi sebagian manusia. Terutama bagi karyawan yang ada di indonesia yang lebih mementingkan urusan pribadinya dan mengabaikan kedisiplinan kehadiran, karena lemahnya system kedisiplinan absensi yang ada di indonesia.

Peranan teknologi informasi terhadap kemajuan suatu organisasi sebagai suatu kebutuhan, sehingga organisasi tersebut memiliki keunggulan kompetitif untuk mampu berdaya saing dengan ditengah-tengah kemajuan yang begitu pesat. Hal ini diwujudkan melalui 
penggunaan system absensi fingerprint. Absensi fingerprint adalah mesin absensi yang cukup modern dengan menggunakan sidik jari sebagai material control pada setiap karyawan, dimana sidik jari tiaptiap orang berbeda. Dalam Dodi R. Setiawan dan Yulianti (2017). Penggunaan absensi fingerprint ini sangat simple dan praktis karena karyawan hanya perlu membuktikan kehadirannya dengan cara menempelkan salah satu jari mereka ke layar monitor. Dengan adanya system absensi fingerprint ini akan lebih menghemat waktu, tenaga, menjamin keamanan, dan lebih akurat dalam menggambarkan kehadiran dan kepulangan karyawan, karena otomatis langsung terekam dalam database (Taufiq et. al , 2021).

Dalam dunia kerja, pada sektor apapun, demi meningkatkan performa dan kinerja karyawan yang pada akhirnya berdampak pada peningkatan hasil baik dari segi kualitas maupun kuantitas, salah satu faktor yang harus diperhatikan adalah kedisiplinan (Sugandi, 2013). Sehingga kinerja perusahaan dapat tercapai lebih optimal dan tercipta hubungan timbal balik yang bersinergi antara karyawan dengan perusahaan". Masalah karyawan merupakan masalah yang membutuhkan perhatian khusus bagi perusahaan (Utomo, 2008)

Absensi dalam ketidakhadiran merupakan sebagai indikator psikologis, penyesuaian medis, atau sosial untuk bekerja. Sering tidak hadirnya seorang karyawan, datang dan pulang tidak sesuai jam kerja, kembali ke kantor setelah jam istirahat melewati ketentuan yang sudah ditetapkan merupakan perilaku yang menunjukan moral buruk(Abdilah \& Wajdi, 2011)

Untuk memperoleh output kinerja dari pegawai negeri sipil yang kuat, kompak dan bersatu padu, memiliki kepekaan, tanggap dan memiliki kesetiakawanan yang tinggi, berdisiplin, serta sadar akan tanggung jawabnya sebagai unsur aparatur negara dan abdi masyarakat diperlukan pembinaan jiwa korps dan kode etik pegawai negeri sipil sesuai dengan yang diatur dalam Peraturan Pemerintah No. 42 Tahun 2004 tentang Pembinaan Jiwa Korps dan Kode Etik Pegawai Negeri Sipil. Selain itu, pendisiplinan pegawai sangat perlu untuk meningkatkan citra kerja, dan kinerja pegawai. Salah satu bagian dalam upaya pendisiplinan tersebut adalah penggunaan alat absensi dalam bentuk finger print.

Faktor lain yang mempengaruhi disiplin kerja adalah motivasi kerja yaitu, keadaan kejiwaan dan sikap mental manusia yang memberikan energi, mendorong kegiatan atau menggerakan dan mengarahkan perilaku kearah yang lebih baik untuk mencapai kebutuhan yang memberi kepuasan atau mengurangi ketidakseimbangan. Menurut Bernard Barelson dan Gary A.Stainer (dalam Sinambela, 2012) dalam Regi Pratama dan Nurbudiawati (2016). Untuk mencapai disiplin kerja yang optimal, pemimpin perlu membimbing, mengarahkan, dan memberi semangat kepada para karyawannya agar mereka mendapatkan motivasi langsung dari atasannya, dengan adanya motivasi langsung dari atasan, karyawan akan mempunyai motivasi kerja yang tinggi dan akan berusaha agar pekerjaannya dapat terselesaikan dengan sebaik-baiknya. Dengan demikian motivasi kerja merupakan suatu pendorong semangat agar seseorang melakukan suatu kegiatan untuk mencapai tujuannya.

Selain dipengaruhi oleh faktor absensi fingerprint dan motivasi kerja, faktor kepemimpinan juga sangat penting dalam meningkatkan disiplin kerja karyawan. Kepemimpinan merupakan kemampuan untuk mengarahkan, memengaruhi, dan menggerakkan tindakan-tindakan seseorang atau sekelompok orang dalam situasi tertentu dan untuk mencapai tujuan tertentu. Menurut Swasto (2011), dalam I Gusti Ngurah Truly Mahendra dan Ida Aju Brahmasari (2014). Dengan kepemimpinan yang baik maka akan membuat karyawan merasa nyaman dalam bekerja dan dapat menciptakan sikap kerja yang memungkinkan adanya penegakan disiplin dalam perusahaan.

Penerapan absensi finger print di Dinas Pemberdayaan Masyarakat dan Desa Provinsi Sulawesi Selatan juga dapat memudahkan atasan untuk melihat tingkat kedisiplinan kehadiran dari masing-masing pegawai. Karena selama ini pada absensi manual, atasan atau pegawai lain yang melihat absensi tidak bisa mengetahui tingkat kedisiplinan pegawai lain, masalahnya pada absensi manual tidak ada keterangan kapan pegawai tersebut datang dan pulang, pegawai bisa merapel di hari lain atau menitip absen pada pegawai lain sehingga menyulitkan atasan untuk memberikan penilaian atau sanksi.

Dalam penelitian yang akan dilakukan peneliti pada penelitian ini adalah berkaitan dengan penggunaan alat teknologi yaitu absensi pegawai secara elektronik (finger print) di dinas Pemberdayaan Masyarakat dan Desa provinsi Sulawesi Selatan. Berdasarkan latar belakang yang telah diuraikan, menjadi dasar untuk melakukan penelitian ini. Karena itu dalam rangka untuk membedah masalah ini peneliti kemudian mengangkat sebuah judul yaitu: Efektifitas Penerapan Finger Print Pada Dinas Pemberdayaan Masyarakat dan Desa Provinsi Sulawesi Selatan. Adapun tujuan dalam penelitian ini yaitu: 1) Untuk mengetahui sistem penerapan absensi finger print pada Dinas Pemberdayaan Masyarakat dan Desa Provinsi Sulawesi Selatan; 2) Untuk mengetahui hambatan dari penerapan absensi finger print pada Dinas Pemberdayaan Masyarakat dan Desa Provinsi Sulawesi Selatan.

\section{METODE}

Dalam penelitian ini penulis menggunakan pendekatan kualitatif. Dengan menggunakan desain penelitian deskriptif dengan pendekatan kualitatif bertujuan untuk menggali mengenai fakta mengenai penerapan finger print pada Dinas Pemberdayaan Masyarakat dan Desa Provinsi Sulawesi Selatan. Penelitian ini akan dilakukan di Dinas Pemberdayaan Masyarakat dan Desa Provinsi Sulawesi Selatan.

Teknik pengumpulan data yang digunakan dalam penelitian ini yaitu: wawancara, observasi, serta 
dokumen. Untuk melakukan proses analisis data, peneliti akan melakukan tiga tahapan proses, yaitu: 1) Tahapan reduksi data (data reduction); 2) Tahapan penyajian data (data display); 3) Tahapan penarikan kesimpulan atau verifikasi (conclusing drawing verivication).

\section{HASIL DAN PEMBAHASAN}

Sistem Penerapan Finger Print di Dinas Pemberdayaan Masyarakat Desa Provinsi Sulawesi Selatan

a. Pencapaian Target

Salah satu indikator penting dalam pelaksanaan absensi elektronik adalah pencapaian target. Pada dinas PMD provinsi Sulawesi Selatan pencapaian target kerjakerja organisasi justru sangat terbantu dan menunjukkan prestasi yang diharapkan.

Dari beberapa pernyataan dari para informan dalam penelitian ini menunjukkan bahwa penerapan absensi finger print pada Dinas Pemberdayaan Masyarakat dan Desa Provinsi Sulawesi Selatan telah terlaksana dengan baik. Penerapan program absensi finger print ini bertujuan untuk meningkatkan disiplin pegawai di Dinas Pemberdayaan Masyarakat dan Desa Provinsi Sulawesi Selatan. Pegawai dituntut untuk melaksanakan tugas dan tanggungjawabnya seperti yang tertuang dalam PP No 53 Tahun 2010 tentang Disiplin Pegawai Negeri Sipill.

Adanya absensi elektronik sangat membantu kerjakerja mereka sehingga target yang sudah dibuat juga dapat dicapai sesuai dengan yang diharapkan. Hal tersebut dapat dicapai karna para pegawai menunjukkan kedisiplinannya dimana mereka antusias untuk melakukan absensi setiap saat sesuai dengan yang sudah ditetapkan.

Dalam melakukan absensi mereka tidak sekedar untuk mendaftarkan dan merekam namanya didalam daftar hadir tetapi sesudah itu mereka langsung bekerja. Dalam rangka memastikan para pegawai bekerja setelah melakukan absensi maka pimpinan dinas PMD provinsi Sulawesi Selatan bersama dengan pegawai lainnya turut bekerjasama untuk saling mengawasi dan melaporkan jika ada pegawai yang hanya sekedar absen tetapi sesudah itu tidak lagi melakukan pekerjaan apapun.

Langka ini dianggap sangat jitu dimana melibatkan pegawai untuk saling mengawasi sesama pegawai sehingga cendrung mereka sulit untuk melakukan kongkalikong. Apalagi untuk melaporkan atau memberikan informasi kepada atasan dari seorang pegawai adalah moment berarti bagi mereka.

Ada yang menarik dilakukan selama ini khususnya selama pandemik covid-19 ini berlangsung, dimana pegawai dianjurkan untuk bekerja dirumah. Selama pandemic covid-19 berlangsung di dinas PMD provinsi Sulawesi Selatan tetap menunjukkan prestasi kelembagaan dimana semua agenda-agenda dinas hampir tidak ada masalah yang berarti terjadi tetapi semuanya berjalan sesuai dengan yang sudah dibuat bersama.

Jika seandainya pegawai hanya untuk senang mengisi absen lalu tidak bekerja, maka kesempatan bekerja dari rumah momentum terbaik jika ingin berlaku curang. Hal tersebut sangat memungkinkan terjadi karna tidak ada pegawai lain yang ikut mengawasi secara langsung termasuk pimpinan. Namun dengan ada prestasi kerja yang terus ditunjukkan oleh para pegawai memberi jawaban secara tidak langsung bahwa mereka benar-benar serius menjalankan pekerjaannya.

b. Kemampuan Adaptasi

Hal lain yang juga penting dalam rangka mengukur efektifitas penggunaan finger print di dinas PMD provinsi Sulawesi Selatan adalah kemampuan adaptasi oleh para pegawai dalam rangka menggunakan alat absensi elektronik tersebut. Berdasarkan hasil wawancara dengan beberapa informan dapat diketahui bahwa pegawai Dinas Pemberdayaan Masyarakat dan Desa Provinsi Sulawesi Selatan sudah mengetahui adanya perubahan penerapan absen manual keabsensi finger print. Meskipun diawal diterapkannya absensi secara elektronik tersebut terdapat pegawai yang belum siap karena tidak mudah untuk menyesuaikan diri. Tetapi dengan adanya pengerahan mengenai penjelasan fungsi dan manfaat penggunaan finger print, pegawai mulai tersebiasa dan lebih disiplin terhadap waktu.

Diawal penggunaan alat ini hampir semua pegawai yang ada di dinas PMD provinsi Sulawesi Selatan mengeluh dan merasa keberatan karna budaya dan cara kerjanya memang sangat berbeda dengan absen manual yang sebelumnya digunakan. Namun lambat laun para pegawai yang ada di dinas PMD provinsi Sulawesi Selatan mampu menyesuaikan diri.

Persoalan paling mendasar dengan adanya absen elektronik dimana absen tersebut tidak bisa diakali seperti absen manual sebelumnya. Artinya jika datang terlambat atau tidak masuk maka para pegawai tidak dapat melakukan absen belakangan. Selain itu jika pada saat absen ternyata datang lewat dari waktu yang ditentukan maka kemudian datanya tidak dapat direkam lagi. Jadi setiap pegawai yang sebelumnya datang pagi tetapi tidak tepat waktu kemudian kemudian tidak lagi dapat melakukan absensi seperti ketika masih menggunakan absensi manual.

Namun setelah berjalannya waktu penerpan finger print tersebut di dinas PMD provinsi Sulawesi Selatan mereka kemudian merasa terbantu termasuk dalam hal pendisiplinan pengawai mereka bekerja. Mereka lebih mampu dan lebih cermat dalam mengatur waktu mereka sehingga antara waktu bekerja dan waktu untuk keperluan lain sudah dapat diseimbangkan.

\section{c. Kepuasan Kerja}

Hal yang sama juga terlihat kepada kepuasan kerja pegawai. Sebagaimana hasil wawancara dengan beberapa informan dapat diketahui bahwa pegawai merasa senang dengan adanya pemberian tambahan kesejahteraan pegawai salah satunya didasarkan kepada absensi dari tiap pegawai sebaliknya jika pegawai yang bersangkutan telat atau tidak absen dianggap tidak hadir pada hari itu juga. Dengan adanya kebijakan tersebut sangat mendukung untuk meningkatkan prestasi kerja yang baik.

Para pegawai merasa lebih adil terhadap penghargaan yang diberikan kepada dirinya atas 
pekerjaan yang telah dilakukannya. Dengan adanya finger print, prestasi kerja mereka salah satunya dihitung berdasarkan kepada jumlah kehadiran yang dibuktikan dengan data yang terekam didalam mesin finger print. Salah bentuk penghargaan terhadap prestasi mereka adalah pemberian tambahan tunjangan penghasilan yang dihitung berdasarkan daftar hadir yang terimput didalam mesin finger print.

Berbeda ketika menggunakan absensi manual sebelumnya dimana kebijaksanaan setiap saat dapat berlaku sehingga untuk menilai prestasi kerja pegawai berdasarkan absensi biasanya tidak berlaku objektif lagi.

\section{d. Tanggung Jawab}

Selain itu hal lan dalam rangka mengukur efektifitas penggunaan finger print di dinas PMD provinsi Sulawesi Selatan adalah tanggungjawab para pegawai. Dari hasil penelitian yang telah dipaparkan sebelumnya bahwa pegawai Dinas Pemberdayaan Masyarakat dan Desa Provinsi Sulawesi Selatan tidak mengalami kendala dengan adanya finger print ini, pegawai telah melaksanakan tugas dan tanggung jawab yang telah diembannya sesuai dengan ketentuan yang telah ditetapkan.

Semua pegawai pada saat setelah melakukan absensi finger print langsung bekerja sesuai dengan beban kerja dan tanggungjawabnya. Dugaan adanya pegawai yang tidak bekerja setelah melakukan finger print di dinas PMD provinsi Sulawesi Selatan hampir tidak kelihatan sama sekali. Hal dapat diminimalisir karna ada sebuah sistem yang diberlakukan oleh pimpinan di dinas PMD provinsi Sulawesi Selatan dimana melibatkan semua pegawai untuk saling mengawasi dan melaporkannya ketika ada yang melanggar ketentuan yang ada.

Tanggungjawab pegawai juga terlihat pada masa pandemi seperti sekarang ini, dimana para pegawai dianjurkan untuk bekerja dari rumah. Pekerjaan yang mereka lakukan dari rumah juga tetap melakukan absensi elektronik melalui aplikasi smart office. Jika mereka tidak memilki tanggungjawab terhadap pekerjaan dan institusinya maka mereka bisa saja mengisi absen lalu tidak melakukan pekerjaan seperti yang dipertanggungkan kepadanya. Tetapi kenyataannya mereka tidak melakukan hal yang demikian.

Hambatan dalam Penerapan Finger Print di Dinas Pemberdayaan Masyarakat Desa Provinsi Sulawesi Selatan

Secara garis besar ada dua hambatan utama efektifitas pelaksanaan finger print pada dinas PMD provinsi Sulawesi Selatan. Hambatan tersebut adalah salah identifikasi dan mesin eror. Salah identifikasi berkaitan dengan data yang tidak sesuai antara pegawai yang melakukan perekaman data dengan nama yang keluar tertera di mesin. Sementara mesin eror adalah keadaan dimana mesin sama sekali tidak dapat digunakan.

Ketika terjadi salah identifikasi maka kemudian pegawai yang melakukan finger print langsung melaporkan kepada atasan untuk dilakukan perbaikan.
Dalam beberapa pernyataan dari para informan bahwa persoalan salah identifikasi kerap terjadi di dinas PMD provinsi Sulawesi Selatan namun hal tersebut bukan merupakan persoalan berarti. Artinya bahwa selama ini masalah tersebut teratasi dengan mudah dan cepat pada instansi ini.

Karena itu langka yang sering dilakukan dalam rangka mengatasi masalah tersebut secara cepat agar supaya tidak mengganggu jam kerja para pegawai adalah dengan mendaftarkan kehadirannya pada absensi manual. Selanjutnya nama-nama yang tidak dapat melakukan absen elektronik tersebut kemudian didaftarkan namanya secara langsung di aplikasi sistem.

Sementara itu persoalan mesin error adalah ketika mesin elektronik dalam keadaan sama sekali tidak dapat dipergunakan. Masalah ini juga kerap terjadi, namun dari pernyataan para informan bahwa hal tersebut bukan masalah besar apalagi pada dasarnya setiap instansi yang juga menggunakan mesin elektronik pasti akan mengalami hal yang sama. Artinya persoalan mesin error adalah masalah alat tersebut secara umum.

Langka yang dilakukan oleh dinas PMD provinsi Sulawesi Selatan ketika terjadi hal demikian adalah melakukan pendaftaran pegawai pada absen manual kemudian datanya dicocokkan untuk didaftarkan secara langsung di dalam aplikasi. Pada prinsipnya hal tersebut dilakukan dalam rangka memastikan bahwa pekerjaan para pegawai tidak akan terganggu sekalipun ada masalah teknis seperti itu.

Namun belakangan ini khususnya di masa pandemi covid-19 dimana para pegawai dianjurkan untuk bekerja dari rumah sehingga merekapun melakukan absen di rumah. Pada dinas PMD provinsi Sulawesi Selatan kemudian diterapkan suatu sistem baru dimana absensi tidak lagi menggunakan sidik jari yang setiap saat harus kekantor terlebih dahulu tetapi sudah menggunakan absensi dengan menggunakan aplikasi yang disebut dengan istilah smart office. Sistem ini cukup dengan menggunakan smartphone lalu kemudian melakukan ceklis secara langsung didalam aplikasi.

Dengan diterapkannya absensi elektronik jenis seperti ini maka persoalan salah identifikasi dan mesin error yang sering terjadi pada alat absensi sidik jari yang berada di kantor yang cara penggunaannya harus ditekan terlebih dahulu menggunakan jari tidak terjadi lagi. Penggunaan finger print melalui sistem smart office jauh lebih akurat dan tingkat kesalahan sangat kecil. Hanya saja kelemahannya adalah belum ada alat yang mampu mendeteksi apakah pegawai tersebut benar-benar bekerja pada saat bekerja dari rumah sehingga layak diterima data kehadirannya pada saat melakukan absensi.

\section{KESIMPULAN DAN SARAN}

Kesimpulan hasil penelitian ini bahwa efektifitas penerapan finger print di Dinas PMD provinsi Sulawesi 
Selatan dapat dilihat berdasarkan sistem penerapan pelaksanaan finger print yang dilakukan di lapangan. Secara garis besar untuk mencermati hal tersebut dilakukan dengan empat indikator yaitu pencapaian target, kemampuan adaptasi, kepuasan kerja dan tanggungjawab. Dalam proses pelaksanaannya keempat indikator tersebut berdasarkan temuan di lapangan semuanya dilakukan dengan baik. Kendatipun ada masalah di lapangan namun hal tersebut hanya merupakan masalah teknis yang dapat diatasi dengan mudah dan cermat oleh instansi tersebut. Hambatan dalam mendukung efektifitas pelaksanaan finger print di dinas PMD provinsi Sulawesi Selatan ada dua yaitu persoalan mesin finger print yang salah dalam melakukan identifikasi data pegawai dan adanya mesin eror. Kedua masalah tersebut tidak menjadi kendala berarti karena setiap ada masalah demikian selalu ditindaki dengan solusi yang tanpa harus mengganggu tugas pokok dari pada para pegawai. Apalagi dengan diberlakukannya sistem baru finger print dimasa pandemi covid-19 sekarang ini di dinas PMD provinsi Sulawesi Selatan yaitu sistem absensi dengan menggunakan smart office dengan menggunakan aplikasi di smartphone. Persoalan mesin secara teknis yaitu salah identifikasi dan mesin eror tidak lagi terjadi.

\section{DAFTAR PUSTAKA}

Abdilah, A. C., \& Wajdi, F. (2011). Pengaruh Kepemimpinan, Stres Kerja, Disiplin Kerja dan Kompesasi dengan Kinerja Pegawai. Jurnal Ekonomi Manajemen Sumber Daya, 12(1), 1- 11.

Mahendra , I Gusti Ngurah Truly dan Ida Aju Brahmasari.

(2014). "Pengaruh Kepemimpinan Terhadap Disiplin Kerja, Motivasi Kerja dan Kinerja Perawat Pelaksana di Ruang Rawat Inap RSJ Menur Surabaya". Jurnal Ilmu Ekonomi \& Manajemen. Untag Surabaya. Vol. 1 No.1.hal. $22-42$

Pratama, Regi dan Nurbudiawati.(2016). "Pengaruh Motivasi Kerja Terhadap Disiplin Kerja Pegawai di Kelurahan Sukakarya Kecamatan Tarogong Kidul Kabupaten Garut".Jurnal Pembangunan dan Kebijakan Publik. Universitas Garut. Vol. 07; No. 02

Setiawan R. Dodi \& Yulianti.(2017). "Pengaruh Absensi Fingerprint terhadap disiplin kerja karyawan pada PT. Sanbio Labolatories Gunung Putri Kabupaten Bogor".Jurnal ilmiah Institut STIAMI.Institut ilmu social dan manajemen STIAMI. Vol.14, No. 01

Sinambela, Lijan Poltak. (2016). Manajemen Sumber Daya Manusia.Cetakan ke 1.Jakarta : PT. Bumi Aksara.

Sugandi. (2013). Pengaruh Kepuasan Kerja Dan Loyalitas Kerja Terhadap Organizational Citizenship Behavior Pada Karyawan Pt . Surya Timur Sakti Jatim. Jurnal Agora, 1(1), 5-10. https://doi.org/10.1016/j.egypro.2016.11.209.

Taufiq, T., Maldun, S., \& Nurkaidah, N. (2021). Komunikasi Aparatur Desa Terhadap Peningkatan
Pelayanan Publik Desa Se-Kecamatan Tellulimpoe Di Kabupaten Bone. Jurnal Paradigma Administrasi Negara, 2(2), 67-73.

Utomo, D. (2008). Pengaruh Jaminan Sosial, K3 Dan Lingkungan Kerja Terhadap Peningkatan Semangat Kerja Karyawan Pada Dinas Pekerjaan Umum Di Boyolali. Universitas Muhammadiyah Surakarta 